\title{
Storm and Stress Period of Adolescent Girls: Parental Concern in Bangladesh
}

\author{
Abul Kalam \\ Lecturer in Sociology, Department of Economics Bangladesh University of Business and Technology (BUBT) \\ Rupnagar, Mirpur-2, Dhaka-1216, Bangladesh
}

\begin{abstract}
The storm and stress period of adolescent is a very important subject for parental concern in Bangladesh. Physical and mental transaction period of adolescent is a dangerous moment every parent faces this situation. Gender inequality is still present in our society. As a result girls are facing the same conflicting situation in this stage of life with their parents. Conflict is a natural phenomenon of every adolescent girl's life. It takes a long time for children to reach adolescence. Adolescence is the period between childhoods roughly from twelve to twenty two years (Gander and Gardiner 1981) of development. Moreover, it is reasonable to refer to the description of the adolescent period by Eriksson (1959b). He has described adolescent as the final stage of childhood. After this stage individual is compelled to make these choices and engaged in a process of preparing for critical decisions in physical, sexual and cognitive transformations, the transaction from childhood through adolescence to adulthood involves major change in personality and social behavior that are influenced by parents, other family members, peers and school. Some are deliberate about marriage and still others drug- addiction, alcoholism etc. (Newman and Newman, 1978). It is therefore, needless to mention, that adolescence is one of the important parts of life span, when individuals prepare themselves for their future adult life. It is well known that, parents are the primary socializing agents to guide, direct the adolescent in general and adolescent girls in particular for being future adults. As such, there might be conflict between adolescent girls with their parents.
\end{abstract}

Keywords: About five key words in alphabetical order, separated by comma

\section{INTRODUCTION}

The adolescents are confronted with a number of social problems. These might create a pressure on them which ends sometimes with conflict. Because present world is more challenging, realistic, side by side, life is now complex and competitive. The post modernism century is the dynamic era of media which effect almost of all classes of people especially on adolescents. The role of media is so strong in changing values, norms, beliefs, cultural and social worlds. In addition it has strong influence of changing parents' norms, values and beliefs. These factors lead to conflict between adolescents as parents. It is an accepted fact that, family is the primary and first institution from where an individual learns norms and values to adjust with wider area of social environment. But sometimes, the psychosocial modes of adolescents of present day might create conflict with their parents. It is also noticed that women are discriminated in each and every sphere of their lives that initiate their backwardness in their household, social, economical and political aspects. In that case conflict becomes inevitable. It is also helpful to reduce conflicting relationship between parents and adolescent children in their families. This study can help parents and others to understand their adolescents better.

Taking the above factors into consideration it was decided to find out the degree of conflicting relationship of the adolescent girls of Shibpur and Monohordi Upazila under Narsingdi district with their parent. It is $t$ noted that some various behaviors of adolescent girls are very common and usual in their everyday lives. These are: Dress choice, Grooming ,Food choice, General health, Liking/disliking friends, Talking over telephone, Mobility, Watching Television movies and reading books, Travelling, Marriage, Family member's attitudes towards boys and girls, Importance to friends than parents while taking any decision ,Feel irritated when parents are not caring, Feel irritated when they are not allowed to watch television etc. Natures of expression to these behaviors by the adolescents and degree of their conflicting relationship with parents were taken into consideration for the present research.

The specific objectives to show the degree of conflicting relationship with parents and understand the importance of friends' in decision making, frank and honest confession after committing and offence, felling irritation in case of parental negligence and imposed restriction in watching television- and conflicting relationship with parents and also prescribe proper suggestions and recommendations for reducing parentadolescent conflict. 


\section{Literature Review}

There are many studies have been done in the respect of the storm and stress period of adolescent: parental concern in Bangladesh. Different researchers have analyzed from different aspects to show such issue. They also made their analysis from different theoretical structure.

Uma D.Krishnan,MS 2004, suggests that the values and attitude of youth may actually exert some influence on parental behavior and viewpoints. In some cases the children may serve as connection to the 'larger world' and the prevailing social and cultural mood of the time. It also shows that generational conflicts are purely a myth, either from the parent's or adolescent viewpoint. Here suggest that the sources of rebellion may include a lack of sufficient freedom to make one's own decision in areas including clothing, hairstyle and choice of friends' a desire to provoke greater parental interest and concerns and a feeling of being over criticized.

Arnett, J.J 1999, in his article Adolescent storm and stress, shown that the degree of conflict between adolescents and parents can fluctuate. Adolescents who have internalized many of the values of a traditional family, for example, show a greater acceptance of parental control than other adolescents..Adolescents difficulties in school, social relationships and other areas appear to occur more frequently in families in which there is parental hostility, rejection or neglect.

Plunked, S. W. 1997, in his article adolescent perception of inter parental conflict, stressor, coping and family life satisfaction shown that the relationship between adolescent perceptions of selected demographic variable (age, two-parent intact families versus single- parent families), inter parental conflict (overt conflict style, conflict about childrearing, conflict about family roles/finance, degree of resolution of conflict), the pileup of stressors, coping strategies (social support coping, detrimental coping), and adolescent family life satisfaction. The sample was comprised of 85 females and 70 males with ages ranging from 14 to 18 years of age (mean $=16.39$ ) from three rural high schools in a south central state. The hypotheses were tested using separate hierarchical multiple regression analysis for adolescent males and adolescent females. Result found that three dimension of inter parental conflict resolution the pile-up of stressors, social support coping strategies, and detrimental coping strategies were significant related to adolescent females' family life satisfaction. For adolescent males, the results found one dimension of inter parental conflict the pile up of stressors, and social support coping strategies were significantly related to family life satisfaction.

Barbara N Allison 2004, in his article parent -adolescent conflict in early adolescences: Research and implications shown that adolescent's feeling of closeness to parents revealed that $47 \%$ of men and $58 \%$ of the women reported feeling very close to both parents before the age of 15 . A similar finding on sex difference occurred in a study of boy's and girl's reported receiving more love, affection, and nurturance from both parents than boys. Boys saw themselves as being treated in more hostile, negative ways by parents. In an earlier generation adolescent were more likely to view the parent's contributions to the family in a positive light 'father' knows best' was a generally accepted standard of family in life.

Margaret Mead 1970 examined this decline in authority in relation to the relevance of parent models. Mead argued that in earlier and more stable era's children as well as adolescent could realistically rely on their parents (as well as other adult figures) as guides for the appropriate social and vocational skills of adulthood.

Laursen,B, Coy,K,C \& Collins,W.A 1994, their article Reconsidering changes in parent-child conflict across adolescence: A meta analysis. (Child development) explained from psychoanalytic point of view the cause of conflict with attention to adolescent development. In this connection they mentioned that"Psychological and behavioral realignment result from psychological maturation. He stated that libidinal urges flood the adolescent, erupting into conflict with parents. Current research suggested that about 80 percent of adolescent are relatively happy and well adjusted. but there are three areas (parent-child conflict, mood change and risky behavior) in which adolescents have greater problems than both younger and older individuals.

UNFPA Population issue Supporting Adolescents and Youth (www Google search), shown that Adolescents confront diverse realities. Differences in age, sex, experience, marital status, interests and preferences, family background, income and religion can place adolescents' worlds apart in terms of what they need and want. The options and constraints they face vary widely as well. Successful programming responds to these varied life circumstances, priorities, interests and preferences. One in every 230 people worldwide is a child or adolescent who has been forced to leave home because of conflicts. Some 30000-child soldiers' are estimated to be involved in ongoing conflicts. A large number of young people suffer from depression. The fact that some 90000 young people commit suicide each year (more than four times that many attempt it) underscores the desperation many young people feel.

Models of Parent Adolescent Conflict: Parents Feelings about Adolescents

The parent's feelings and personal development have some bearing on the production of conflict. Most parents if not all, feel ambivalent about seeing their children become adults. They have tried to prepare their children for independence for many years. Success, however, means the end of job of parenthood. Viewing the almost finished product at 18 or so it occurs to so two fold. 
Firstly, it seems as though a little more control and direction might improve the son/daughter to the point where future success would be assured. The parents then continue to try to make decision which the youngster knows he himself must make in order to establish the adult identity firmly.

Secondly, the imperfection of the childhood may reactivate the parents own adolescent feelings, the fears and pains they know, their unsolved problems which were almost forgotten until now. Parents simply try to protect their children from dangers they know to be much more serious than the children from dangers they know to be much more serious than the children realize.

\section{Methodology}

The present study is attempt to understanding the adolescent views and parent-adolescent conflict in Narsingdi district. After the identification of the problem and subject matter of the research, the next important task is to determine the appropriate method of the study. Because of an accurate result may be obtained if appropriate methodology is applied. In this research Survey method and Case study methods are used. In that part various table and explanation are given for better understanding about the storm and stress period of adolescent: Parental Concern in Bangladesh. There are various types of people live in the society. Among them adolescent are mostly vulnerable. They face numerous problems such as social, physical and so on. But it can't express totally in numerical values. There is also need to assess subjective factor that is related to parentadolescents conflicts. For the above variation, mixed method has applied in the study.

\section{General Discussion}

Adolescence: Adolescence is the bridge between childhood and adulthood. The sex-organs mature, sex characteristics appear, height and weight increase dramatically. Some people confuse the terms 'adolescence' and puberty'. Adolescence can be defined as the period from the onset of puberty to adulthood. Puberty is the starter period of adolescence during which an individual reaches sexual maturity. It lasts from 2-4 years and behavior become more mature. But the outward signs of the development of sex organs and a mature body type are not the first physical changes in adolescence. Many months before those outward signs become visible, the body changes in an unseen way. The period of adolescence requires continued refinement and application of these skills to self-definition in relation to the culture. In western society it begins at about the age of 12-19 years and ends at either the late teens or early twenties (Papilla and olds 1981). UNFPA follows the age distribution for Adolescence: 15-24 year olds (early adolescence 10-14 and late adolescence 15-19), Youth: 1524 year olds, Youth people: 10-24 years old.

Adolescent's views: Adolescents' views are expressed thorough different ways. But adolescent is the age of conflicting. So adolescents conflicting views can be expressed through mood disruption and risk behavior. Adolescent tend to be more volatile emotionally than either children or adults. They experience more extremes of mood and more swings of mood from one extremes of mood to the other. Adolescents have higher rates of reckless, norm-breaking and anti-social behavior than both adult and children.

Parent's- Adolescent Relationships: Parent child relationships change during adolescent from protection dependence to affection. The change involves turmoil in parent and child as they learn to play new roles and new feelings as the child establishes a mature sense of identity.

Parents -adolescent conflict: Adolescent have a tendency to be rebellious and to resist adult authority. In particular adolescence is a time when conflict with parents is especially high.

Parents-Adolescent Conflict Models: There are three models of Parents-Adolescent Conflict; SocialBiological Model, Cognitive Development Model and Social Relational Model.

Social-Biological Model: The beginning of biological maturation leads to increase in conflict with parents. Adaptive evolutionary features ensure the adolescent to less time spent with parents and more time with peers or individuals outside of the family. Once distance is achieved conflict subsides.

Cognitive Development Model: The cognitive development and intellectual maturation, results in the new understanding of the self and relationships, leading to change in perspective towards parents. It states that conflict affects is highest in middle adolescence and lowest in late adolescence as issues and roles are renegotiated. Children see parents as equals but parent's disinclination to accept this leads to more conflict until the relationship becomes more horizontal. Intellectual advance also indicate a use of more effective resolution strategy. 
Social Relational Model: According to Social Relational Model Adolescent behavior changes with the relationship, which means that they must integrate their goals and behaviors producing conflict? But because of the investment in the relationship each party will try to minimize the negative impacts of conflict.

From the study of these models, it can be concluded that conflict occurs from biological, social or intellectual maturation or changes in the relationship. Each of the models explains conflict as an unavoidable component of adolescence.

Biological Component

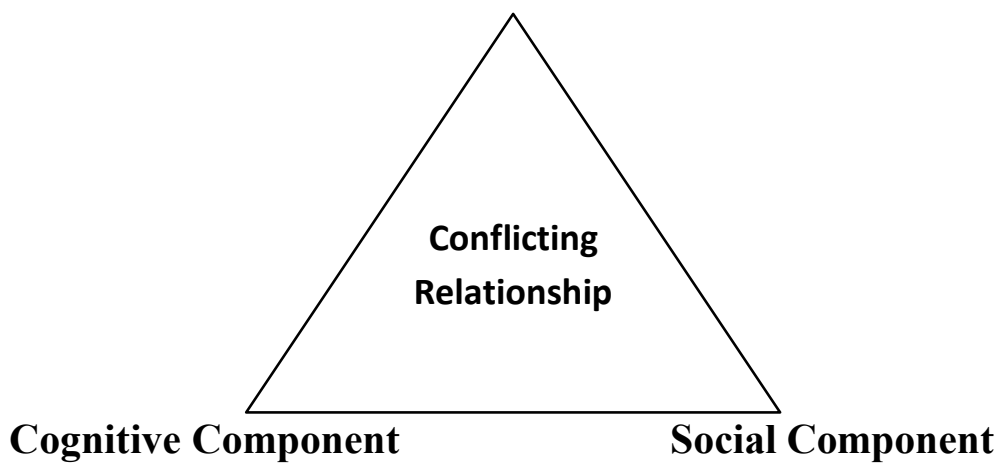

Conceptual framework:
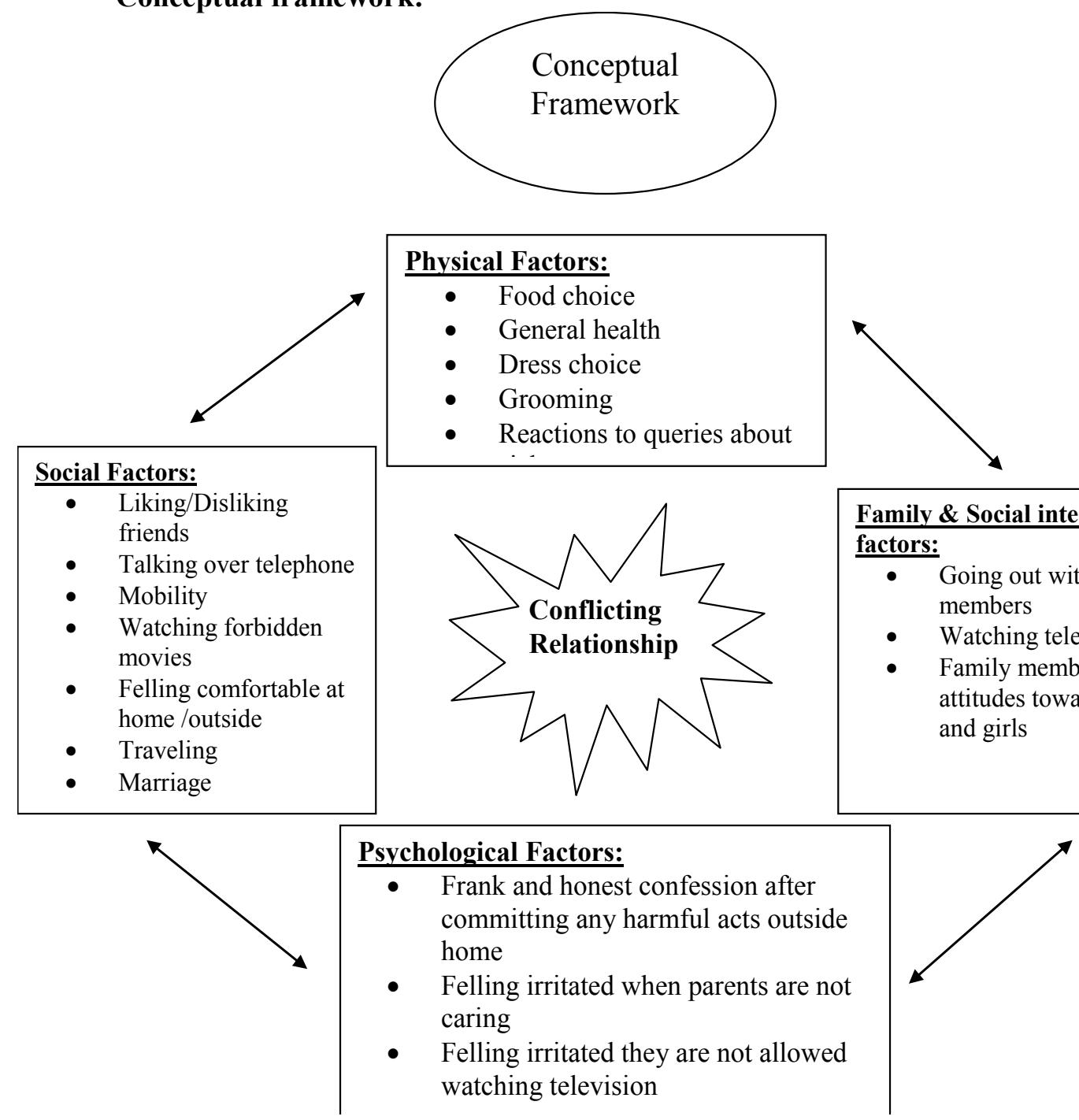


\section{The Study Area And Population}

The first and my foremost duty for a researcher duty a researcher is to select of the study area. Present study is performed at Shibpurpur and Monohordy Upazila under Narsingdi district. Data were collected from the selected area which contains not less than 850 to 950 families with around 2550 to 3000 adolescents' girls. The study area was selected because it is the significant areas of Bangladesh. Moreover, based on the rationale of the study the study population was adolescent girls, parents and availability and cooperation of the people to participate in the study. In this study, we employ stratified sampling because Narsingdi district is divided into two parts. A total number of 120 adolescent girls of class viii and xii have selected from the research areas. For this present explanatory study, the obtained data was produced in number and percentage according to the objective of the study and case studies has used presented in descriptive form as those received from the respondents.

\section{1 Demographic Profile of the Respondents}

5.1.1 Adolescent girl's preferences of friends over parents:

With regard to social information, one of the important questions was asked to the adolescent girls about their preferences of friends over parents. The answer given by adolescent girls are present in the following table shows that most of the adolescent girls $\mathrm{N}=94(78.3 \%)$ likes their parents more than friends, while $\mathrm{N}=14$ (11.7\%) like their friends more than their parents. In addition that, $\mathrm{N}=5(4.2 \%)$ adolescent girls like their parents equally, $\mathrm{N}=1(.8 \%)$ adolescent girls sometimes like their friends more than parents and only two like mother only as well as four respondents out of responding.

Table 5.1.1 Number and percentage distribution of adolescent girl's preferences of friends over parents

\begin{tabular}{|l|l|l|}
\hline Responses & Number & Percentage \\
\hline Like parents more & 94 & 78.3 \\
\hline Like friends more & 14 & 11.7 \\
\hline Like mother only & 2 & 1.7 \\
\hline Like friends more sometimes & 1 & .8 \\
\hline Like both equally & 5 & 4.2 \\
\hline No response & 4 & 3.3 \\
\hline Total & $\mathbf{1 2 0}$ & $\mathbf{1 0 0}$ \\
\hline
\end{tabular}

The findings regarding liking/disliking friends reveal that almost all the respondents in favor of liking parents more than the friends. This indicates more respect to the parents by the children in our society.

5.1.2 Adolescent girls by their liking to talk with their friends of opposite sex:

Table-5.1.2 Number and percentage distribution of adolescent girls by their liking to talk with their friends of opposite sex over telephone

\begin{tabular}{|c|c|c|}
\hline Responses & Number & Percentage \\
\hline Like to talk with their friends & 28 & 23.3 \\
\hline Do not like to talk with their friends & 79 & 65.8 \\
\hline Specially with one & 1 & .8 \\
\hline If person is familiar & 5 & 4.2 \\
\hline Sometimes like to talk with their friends & 4 & 3.3 \\
\hline No telephone & 2 & 1.7 \\
\hline No responses & 1 & .8 \\
\hline Total & 120 & 100 \\
\hline
\end{tabular}

An interesting question was asked about liking to talk with friends of opposite sex over telephone. In this table shown that a majority of the adolescent girls $\mathrm{N}=79(65.8 \%)$ does not like to talk with their friends of opposite sex, while $\mathrm{N}=28(23.3 \%)$ adolescent girls like to talk with their friends of opposite sex. A few of them $\mathrm{N}=5(4.2 \%)$ talk with opposite sex if the person is familiar and $\mathrm{N}=4(3.3 \%)$ sometimes like to talks with their friends of opposite sex, and only one like to talk especially with one person. Details of the responses given by adolescent girls are shown in table. Result about liking to talk with their friends of opposite sex over telephone show that a majority of the adolescent girls does not like to talk with their friends, while some of them showed liking to talk with their friends. This is to be explained in terms that they consider that the telephone should be used only for emergency purpose only.

\subsubsection{Adolescent girls by giving importance to the family rules/customs of returning home at 7'o clock:}

Adolescent girls were also asked about their giving importance to the family customs of returning home by 7'o clock. The result in this connection show that most of the adolescent girls $\mathrm{N}=108(90 \%)$ gave 
importance to the family custom of returning home by 7'o clock for security. A few of them $\mathrm{N}=6(5 \%)$ do not give importance to this family system; details of responses given by the adolescent girls are given in the following table.

Table5.1.3 Number and percentage distribution of adolescent girls by giving importance to the family custom of returning home at 7'o clock

\begin{tabular}{|l|l|l|}
\hline Responses & Number & Percentage \\
\hline Give importance & 108 & 90 \\
\hline Do not give importance & 6 & 5 \\
\hline Sometimes give importance & 4 & 3.3 \\
\hline No response & 1 & .8 \\
\hline Do not know & 1 & .8 \\
\hline Total & $\mathbf{1 2 0}$ & $\mathbf{1 0 0}$ \\
\hline
\end{tabular}

From the above table it seems that, most of the adolescent girls follow the rule /custom of family for returning home. Only few numbers of adolescent girls do not follow the family customs of returning home before 7'o clock.

\subsubsection{The adolescent girls to watch films or read books which are not acceptable to family/societal norms:}

The table 5.1.4 reveal that most of the adolescent girls $\mathrm{N}=108(90 \%)$ were found not eager to watch socially unacceptable movies or films and read the book which are unacceptable to society and family. only a few number of adolescent girls are interested to read the books and watch the films or which are forbidden by family or society $(\mathrm{N}=5)$. The another number of adolescent girls who are sometimes watch socially unacceptable films and movies.

Table 5.1.4 Number and percentage distribution of adolescent girls to watch socially unacceptable films and reading book curiosity

\begin{tabular}{|l|c|c|}
\hline Responses & Number & Percentage \\
\hline $\begin{array}{l}\text { Curiosity socially unacceptable films or books which are not acceptable } \\
\text { to societal norms. }\end{array}$ & 4.2 \\
\hline $\begin{array}{l}\text { Not curiosity to films or books which are not acceptable to } \\
\text { Societal norms. }\end{array}$ & 108 & \\
\hline Sometimes curious to socially unacceptable films or books. & 3 & \\
\hline No responses & 4 & 2.5 \\
\hline Total & $\mathbf{1 2 0}$ & 3.3 \\
\hline
\end{tabular}

Here majority of the respondents showed no curiosity films or books which are not acceptable to societal norms. This may be due to that they have learned and developed values and practice not to see the movies that are not approved by society.

\subsubsection{Adolescent girls by their comfortableness to outside environment than inside:}

Adolescent girls were also asked about their comfortableness $\mathrm{s}$ to the environment outside than inside home. Table 5.1.5 shows that a majority of adolescent girls $\mathrm{N}=68(56.7 \%)$ expressed their feeling of comfortableness at home rather than outside while some of them $\mathrm{N}=40(33.3 \%)$ were found to feel less comfortable at home rather than outside. Table also shows that $\mathrm{N}=10(8.3 \%)$ feel comfortable both at home and outside.

Table 5.1.5 Number and percentage distribution of adolescent girls by their comfortableness to outside than home environment

\begin{tabular}{|l|c|c|}
\hline Responses & Number & Percentage \\
\hline Comfortableness to environment outside home & 40 & 33.3 \\
\hline Comfort at home environment & 68 & 56.7 \\
\hline Comfort both outside and inside at home & 10 & 8.3 \\
\hline No responses & 2 & 1.7 \\
\hline Total & $\mathbf{1 2 0}$ & $\mathbf{1 0 0}$ \\
\hline
\end{tabular}

It is positive and affirmative findings that a majority of the adolescent girls responded that they feel more comfortable at home environment compare to outside. That means both parents and adolescent have some interest to keep relationship and bondage with each other.

\subsubsection{Adolescent girls by their friendly relationship with parents:}

In the present research, adolescent girls were asked about their friendly relationship with their parents. Findings concerning this depict that majority of adolescent girl $\mathrm{N}=80(66.7 \%)$ were friendly with their parents 
while a few of them $\mathrm{N}=23(19.2 \%)$ were not friendly relationship with their parents. Moreover, it was also revealed that a few of the adolescent girls $\mathrm{N}=8(6.7 \%)$ were friendly relationship with their only, while a few of them $\mathrm{N}=7(5.7 \%)$ have moderate friendship relationship with their parents.

Table 5.1.6 Number and percentage distribution of adolescent girls' friendly relationship with their parents

\begin{tabular}{|l|l|l|}
\hline Responses & Number & percentage \\
\hline Friendly with parents & 80 & 66.7 \\
\hline No friendship with parents & 23 & 19.2 \\
\hline Friendly with mother only & 8 & 6.7 \\
\hline Moderate friendship & 7 & 5.7 \\
\hline No responses & 2 & 1.7 \\
\hline Total & $\mathbf{1 2 0}$ & $\mathbf{1 0 0}$ \\
\hline
\end{tabular}

In the question of friendly relationship, the results reveal that a majority of the adolescent girls have friendly relationship with their parents. This can also be explained in terms of showing some interest to keep healthy relationship and bondage with each other. It also indicates that there is no conflicting relationship between adolescent girls and their parents.

\subsubsection{Adolescent girls by their liking to travel everywhere with their parents:}

Adolescent girls' liking to travel everywhere with their parents were also enquired in this research. In this context, Table 3.1.7 indicates that a majority, $\mathrm{N}=62(51.7 \%)$ adolescent girls showed their likings to travel with their parents and $\mathrm{N}=51(42.5 \%)$ do not like to travel with them. Moreover, $\mathrm{N}=2(1.7 \%)$ were found to travel in some places, while $\mathrm{N}=3(2.5 \%)$ and $\mathrm{N}=2(1.7 \%)$ by terns, do not like to travel to their parents at every places and not answering.

\subsubsection{Table -Number and percentage distribution of adolescent girls by their liking to travel} everywhere with their parents

\begin{tabular}{|l|l|l|}
\hline Responses & Number & Percentage \\
\hline Like to travel with parents & 62 & 51.7 \\
\hline Do not like to travel with parents & 51 & 42.5 \\
\hline In some places & 2 & 1.7 \\
\hline Not all places & 3 & 2.5 \\
\hline No responses & 2 & 1.7 \\
\hline Total & $\mathbf{1 0 0}$ & $\mathbf{1 0 0}$ \\
\hline
\end{tabular}

The findings with respect to adolescents girls liking to travel everywhere with their parents indicate that a majority of the adolescents girls preferred to travel outside with their friends, while a significant number of adolescent girls did not like to travel with their parents. The results in this connection confirm the peer group feeling of the adolescents.

\subsubsection{Friend likes for adolescent girls parents:}

One question was asked to adolescent girls in this study to know their friend likes for their parents. In this respect, almost all adolescent girls $\mathrm{N}=112(93.3 \%)$ responded that their friends like their parents, while a very few them $\mathrm{N}=2(1.7 \%)$ don't like their parents. The findings regarding adolescent girls 'friends liking and not liking parents are presented in the following table

Table 5.1.8 Number and percentage distribution of adolescent girls by their friend likes for their parents.

\begin{tabular}{|l|l|l|}
\hline Responses & Number & Percentage \\
\hline Like parents & 112 & 93.3 \\
\hline Do not like parents & 2 & 1.7 \\
\hline No responses & 4 & 2.5 \\
\hline Do not know & 2 & 1.7 \\
\hline Total & $\mathbf{1 2 0}$ & $\mathbf{1 0 0}$ \\
\hline
\end{tabular}

From the above table it seems that, most of the adolescent girls' friends like their parents. This indicates good relationship among the friends and cultural values in society.

5.1.9 Adolescent girls in offering decision in family matter:

An important issue on adolescent girl's role in offering decision in family matters was also asked in this study. The result indicate that the majority of the adolescent girls $\mathrm{N}=74(61.7 \%)$ can decision in their family matter. some of them $\mathrm{N}=29(24.1 \%)$ cannot give any decision in their family matter and some of them can give 
decision sometimes.

Table5.1.9- Number and percentage distribution of adolescent girls in offering decision in family matters.

\begin{tabular}{|l|l|l|}
\hline Responses & Number & Percentage \\
\hline Can offer decision & 74 & 61.7 \\
\hline Cannot offer decision & 29 & 24.1 \\
\hline Sometimes offer decision & 14 & 11.7 \\
\hline No responses & 2 & 1.7 \\
\hline Do not know & 1 & 0.8 \\
\hline Total & $\mathbf{1 2 0}$ & $\mathbf{1 0 0}$ \\
\hline
\end{tabular}

The result reveal that majority of the adolescent girls can offer decision in the family matters. This is positive sign in our culture for gender equality.

\subsubsection{Acceptance of adolescent girls given decision:}

Relating to the above issue, adolescent girls were asked the acceptance of their given decision. Findings concerning this matter depict that decision are accepted for $\mathrm{N}=50(41.7 \%)$ adolescent girls. Sometimes their decision is accepted and their decision is rejected $\mathrm{N}=27(22.5 \%)$ of adolescent girls. The details are given the following table-

Table- 5.1.10 Number and percentage distribution of acceptance of adolescent girls given decision

\begin{tabular}{|l|l|l|}
\hline Responses & Number & Percentage \\
\hline Decision accepted & 50 & 41.7 \\
\hline Decision are not accepted & 27 & 22.5 \\
\hline Sometimes accepted & 25 & 20.8 \\
\hline If decision are reasonable & 6 & 5 \\
\hline Not always & 10 & 8.4 \\
\hline No response & 1 & .8 \\
\hline Do not know & 1 & .8 \\
\hline Total & $\mathbf{1 2 0}$ & $\mathbf{1 0 0}$ \\
\hline
\end{tabular}

The findings relating to acceptance of the decision given by the adolescent girls show that a significant number of adolescent girls' decision is accepted and some of their decisions are reasonable and practical. This indicates that familiar is gradually changing positively to values the opinion of their female adolescent girls

5.1.11Adolescent girls by their feeling off sadness when they are not allowed to go outside:

Table 3.1.11 Number and percentage distribution adolescent girls by their feeling of sadness when they are not allowed to go outside

\begin{tabular}{|l|l|l|}
\hline Responses & Number & Percentage \\
\hline Creates feeling of sadness & 90 & 75 \\
\hline Create no feeling of sadness & 18 & 15 \\
\hline Sometimes create feeling of sadness & 8 & 6.7 \\
\hline Afraid of seeking permission & 1 & .8 \\
\hline No such situation arises & 3 & 2.5 \\
\hline Total & $\mathbf{1 2 0}$ & $\mathbf{1 0 0}$ \\
\hline
\end{tabular}

Adolescent girls of this research were also enquired about their feeling when they are not permitted to go outside. The result indicate that $\mathrm{N}=90(75 \%)$ adolescent girls feel sad while $\mathrm{N}=18(15 \%)$ adolescent girls said that it does not create any sort of sadness. Furthermore, $\mathrm{N}=8(6.7 \%)$ adolescent girls mentioned that sometimes they feel sad while $\mathrm{N}=3$ pointed out that no situation arises. It also interesting to mention here one adolescent girls feel afraid of seeking permission from her parents to go out. In connection with adolescent girl's feelings, it appears that a large number of them expressed their feeling of sadness when they are not allowed to go outside. It shows the common and usual feeling for individual especially for the adolescents when some of the desire are not fulfilled.

\subsubsection{Adolescent girls accompanying somebody while going out:}

The adolescent girl were asked a question, whether anybody accompanies them while they go out. Answering to the question, $\mathrm{N}=53(44.2 \%)$ adolescent girls expressed that somebody accompanies them while going out and a slightly higher number of adolescent girls $\mathrm{N}=57$ answered that nobody accompany while they go out. Only $\mathrm{N}=9$ expressed that sometimes they go out with accompanies. 
Table 5.1.12 Distribution the numbers of adolescent girls go out accompany with somebody

\begin{tabular}{|l|c|c|}
\hline Responses & Number & Percentage \\
\hline Accompanied by somebody while going out & 53 & 44.2 \\
\hline Nobody accompanied & 57 & 47.5 \\
\hline Sometimes accompanied while going out & 9 & 7.5 \\
\hline No responses & 1 & .8 \\
\hline Total & $\mathbf{1 2 0}$ & $\mathbf{1 0 0}$ \\
\hline
\end{tabular}

According to the result about adolescent girls' going out, some of them are accompanied by some body, while some of them are not accompanied while going out. This may be explained in terms of differences of rule and customs in different families.

\subsubsection{Parents liking or disliking towards having fun with friends:}

5.1.13 -Number and percentage distribution of adolescent girls by liking and disliking of their parents while they are making fun with their friends

\begin{tabular}{|c|c|c|}
\hline Responses & Number & Percentage \\
\hline Like having fun with friends & 31 & 25.8 \\
\hline Do not like having fun with friends & 72 & 60 \\
\hline Like having fun where necessary & 2 & 1.7 \\
\hline Like fun with limitation & 13 & 10.8 \\
\hline No responses & 1 & .8 \\
\hline Do not know & 1 & .8 \\
\hline Total & $\mathbf{1 2 0}$ & $\mathbf{1 0 0}$ \\
\hline
\end{tabular}

In this study, a question was asked to the respondents regarding their parents' liking and disliking when they making noise and shouting with their friends. They answered given by respondents reveal that $\mathrm{N}=72 \mathrm{do}$ not like to make noise with their friends, while $\mathrm{N}=31$ like to make noise to their friends. $\mathrm{N}=13$ adolescent girls responded that their parent like to make noise with their friends in a limited scale while only two said their parents like to make noise where they feel necessary.

Finding about liking and disliking parents for their adolescent girls' enjoyment with friends show that most of their parents do not like making noise and shouting with their friends while some them in limitation scale. Moreover, a few of them consider when it is necessary. The results indicate the common and usual behavior expressed by their parents.

\subsection{Adolescent girls Food Habits}

5.2.1 Adolescent girls' preference for food:

Responses to the question of liking of food, majority of the adolescent girls $\mathrm{N}=69$ answered in favor of homemade food, $\mathrm{N}=36$ respondents food of outside and $\mathrm{N}=12$ all type of food.

Table 5.2.1 the distribution of adolescent girls by their liking of foods

\begin{tabular}{|l|l|l|}
\hline Types of food & Number & Percentage \\
\hline Homemade food & 69 & 57.5 \\
\hline Food from outside & 36 & 30 \\
\hline All types & 12 & 10 \\
\hline Others & 3 & 2.5 \\
\hline Total & $\mathbf{1 2 0}$ & $\mathbf{1 0 0}$ \\
\hline
\end{tabular}

Considering food habits, the result reveal that a majority of adolescent girls preferred homemade food. A few of adolescent girls like food from outside. This indicates the deep feeling of love and affectionate relationship between parents and adolescent girls.

\subsubsection{Adolescent girls' reaction when parents force them to eat nutritional food:}

Another question was asked to the adolescent girls to know the reaction when parents force or insist on eating nutritional food. Answering given by the respondents indicate that $\mathrm{N}=48$ adolescent girls become irritated, $\mathrm{N}=21$ become pleased, while $\mathrm{N}=45$ showed no reaction. Only four respondents said sometimes become irritated and only 2 showed no pressure is given for taking nutritional food. 
Table5.2.2 Number and percentage distribution of adolescent girls' reaction when to take Nutria's food

\begin{tabular}{|l|l|l|}
\hline Responses & Number & percentage \\
\hline Become irritated & 48 & 40 \\
\hline Become pleased & 21 & 17.5 \\
\hline No reaction & 45 & 37.5 \\
\hline Sometimes become irritated & 4 & 3.3 \\
\hline No pressure is given & 2 & 1.7 \\
\hline Total & $\mathbf{1 2 0}$ & $\mathbf{1 0 0}$ \\
\hline
\end{tabular}

Findings about adolescent girls' reaction indicate that a large number of adolescent girls become irritated when parents insist on eating nutritious food. Furthermore, some of them become pleased if they are forced to take nutritious food. Because of individual differences various type of reaction were found to insisting to taking nutritious food.

\subsubsection{Agreement of opinion with parents concerning types of dress:}

To see the agreement or disagreement between the adolescent girls and their present regarding the type of dress adolescent wear was one the concerns of this present research. Answers given by the adolescent girls indicate that the majority of the adolescent girls $\mathrm{N}=82$ showed their agreement with their parents regarding the types of dresses, of which $\mathrm{N}=26$ strongly agree and $\mathrm{N}=56$ agree with their parents in dress choice. On other hand, $\mathrm{N}=23$ disagree and $\mathrm{N}=5$ strongly disagree with their parent in dress choice. Only seven respondents said they sometimes agree with their parents in dress choice.

Table 5.2.3 the distribution of adolescent girls by the agreement with parents concerning dresses

\begin{tabular}{|l|l|l|}
\hline Responses & Number & Percentage \\
\hline Strongly agree & 26 & 21.7 \\
\hline Agree & 56 & 46.7 \\
\hline Disagree & 23 & 19.2 \\
\hline Strongly disagree & 5 & 5.2 \\
\hline Sometimes agree & 7 & 5.8 \\
\hline No limitation & 1 & 0.8 \\
\hline No responses & 1 & 0.8 \\
\hline Do not know & 1 & 0.8 \\
\hline Total & $\mathbf{1 2 0}$ & $\mathbf{1 0 0}$ \\
\hline
\end{tabular}

Concerning the dress choice, majority of the adolescent girl's said there is an agreement with their parents regarding the types of dresses' they wear. On the other hand, a few of the adolescent girls mentioned that there is no limitation to wear any type of dress. The findings indicate that parents support their adolescent girl's choice of dress. They are in favor of fulfillment children's wish to type of dress they want to wear.

\subsubsection{Agreement of opinion with parent concerning good grooming:}

Table 5.2.5 Number and percentage distribution of adolescent girls by their agreement with parents concerning good grooming

\begin{tabular}{|l|l|l|}
\hline Responses & Number & Percentage \\
\hline Strongly agree & 21 & 17.5 \\
\hline Agree & 56 & 46.7 \\
\hline Disagree & 27 & 5 \\
\hline Strongly disagree & 6 & 5 \\
\hline Sometimes agree & 6 & 0.8 \\
\hline Parents have no concern & 1 & .8 \\
\hline Emphasis on self choice & 1 & .8 \\
\hline No responses & 2 & $\mathbf{1 0 0}$ \\
\hline
\end{tabular}

The respondents were asked a question regarding their agreement with parents concerning good grooming, most of the adolescent girls responded that parents showed agreement with them concerning their grooming. Furthermore, illustrate that $\mathrm{N}=21$ adolescent girl's parents strongly agree with them and $\mathrm{N}=56$ agree with them. The table also shows that $\mathrm{N}=27$ adolescent girls responded that their parents disagree and $\mathrm{N}=6$ strongly disagree as well as $\mathrm{N}=6$ sometimes agree with them regarding their grooming. One said her parents have no concern and one said her parent emphasis her choice regarding good grooming. Finding concerning good grooming, the result indicate that most of the adolescent girls responded that parent showed agreement. A very few of adolescent girls mentioned that their parents put more emphasis on their adolescent girls' likings, similar to dress choice; it was revealed that the parents support their adolescent girls' liking of grooming. It indicates that the parents consider their adolescent liking. 


\subsection{Psychological information}

5.3.1 Adolescent girls' importance to friends rather than parents while taking decisions for themselves:

In this research, it was aimed to reveal whether the adolescent girls give more importance to friends than their parents while taking decision for themselves. The result in this regard illustrate that a vast number of adolescent girls $\mathrm{N}=84$ are in favor of giving more importance to their parents and $\mathrm{N}=31$ were in favor of giving more importance to their friends while decision for themselves. Table also shows that $\mathrm{N}=3$ adolescent girls give more importance to themselves, while one emphasis on elder brother.

Table-5.3.1 the distribution of adolescent girls by giving preference friends than parents while taking decisions for themselves

\begin{tabular}{|l|l|l|}
\hline Responses & Number & Percentage \\
\hline Giving more importance to their friends & 31 & 25.8 \\
\hline Giving more importance to their parents & 84 & 70 \\
\hline By self & 3 & 2.5 \\
\hline No responses & 1 & .8 \\
\hline Giving to elder brother & 1 & .8 \\
\hline Total & $\mathbf{1 2 0}$ & $\mathbf{1 0 0}$ \\
\hline
\end{tabular}

About taking decision for adolescent girls themselves, a large majority of them were in favor of giving more importance to their parents and some of them were in favor of giving importance to their friends. The results also show a few of them put importance to their elder brothers to take decision for on their parents and family to take decisions about themselves. This show a sort of family attachment in our society

\subsubsection{Parents' annoyance to the psychosocial behavior of the adolescent girls:}

The information on parents' expression of annoyance to their adolescent girls was also collection for the purpose of the present research. According to the responses given by the adolescent girls if came out that $\mathrm{N}=80$ positive attitude to their adolescent girls where $\mathrm{N}=26$ do not express positive attitude to their children $. \mathrm{N}=9$ adolescent girls confessed that they faced both positive and negative attitude from their parents and the others are given in the following table.

\subsection{2-Number and percentage distribution of adolescent girls by their parents' expression of} annoyance to their psychological behavior

\begin{tabular}{|l|l|l|}
\hline Responses & Number & percentage \\
\hline Express annoyance & 26 & 21.7 \\
\hline Do not express annoyance & 80 & 66.7 \\
\hline Don't do anything that disliked by parents & 1 & .8 \\
\hline To move forward more & 1 & .8 \\
\hline Both positive and negative & 9 & 7.5 \\
\hline No response & 2 & 1.7 \\
\hline Do not responses & 1 & .8 \\
\hline Total & $\mathbf{1 2 0}$ & $\mathbf{1 0 0}$ \\
\hline
\end{tabular}

Concerning parent's expression of annoyance to their adolescent's psychological behavior, majority of them did not express annoyance and few of them show annoyance to them. Moreover it was found out that they use to give move forward. This confirms that present now-a-days do not feel sad and discourage if they have girl adolescents.

5.3.3 Adolescent girls by frank and honest confession to their parents after committing any mistake or harm to anybody outside the home:

It was attempted in the present study to understand adolescent girls' confession to their parents after committing any mistake or harms to somebody. It is found that a large majority of adolescent girls $\mathrm{N}=85$ confess to their parents frankly and honestly after doing wrong and hurting someone outside the home and only a very few of them that is $\mathrm{N}=19$ do not admit such thing frankly. Moreover, the results show that $\mathrm{N}=7$ adolescent girls sometimes confess to their parents $=4$ do not harm anybody $=1$ mentioned that no such situation arises others are given in the below- 
Table-5.3.3 number and percentage distribution of adolescent girls' frank and honest confession to their parents after committing any mistake or harm anybody outside of home

\begin{tabular}{|l|l|l|}
\hline Responses & Number & percentage \\
\hline Confess frankly to parents & 85 & 70.8 \\
\hline Do not confess frankly to parents & 19 & 15.8 \\
\hline Sometimes confess & 7 & 5.8 \\
\hline Tell mother & 1 & .8 \\
\hline Situation does not arise & 1 & .8 \\
\hline Don't harm any body & 4 & 3.3 \\
\hline Confess to sister in law & 1 & .8 \\
\hline No responses & 2 & 1.7 \\
\hline Total & $\mathbf{1 2 0}$ & $\mathbf{1 0 0}$ \\
\hline
\end{tabular}

According to findings, a large majority of adolescent girls expressed that they use to confess frankly and honestly to their parents after committing any mistake or harm anybody outside the home. Moreover, some of the respondents expressed that there was no such experience and they did not harm anybody. This is an encouraging and optimistic point that our adolescent holds positive and moral values in their youth lives.

\subsubsection{Adolescent girls' feeling of irritation when parents are not caring for them:}

Adolescent girls were also questioned about their feeling when their parents are not caring for them. Finding presented in the following table indicate that majority $=63$ of adolescent girls feel irritated $=45$ adolescent girls do not feel irritated, a very few of them $\mathrm{N}=4$ mentioned that sometimes they feel irritated. Moreover, the table indicates that $\mathrm{N}=2$ adolescent girls said that they were not in such a situation and only $\mathrm{N}=2$ feel sad if they are not cared for by their parents.

Table-5.3.4 number and percentage distribution of adolescent girls by their feeling of irrigation when their parents are not caring about themselves

\begin{tabular}{|l|l|l|}
\hline Responses & Number & percentage \\
\hline Feel irritated & 63 & 52.5 \\
\hline Do not feel irritated & 45 & 37.5 \\
\hline Sometimes feel irritated & 4 & 3.3 \\
\hline Feel sad & 2 & 1.7 \\
\hline Situation not arise & 2 & 1.7 \\
\hline No responses & 4 & 3.3 \\
\hline Total & $\mathbf{1 2 0}$ & $\mathbf{1 0 0}$ \\
\hline
\end{tabular}

Findings about adolescent girls' feeling showed that majority of them feel irritated and few of them do not feel such if their parents are not caring about themselves. This supports that children and adolescent need proper care and attention from their parents.

\subsubsection{Parents' showing irritation if adolescent girls read books other than textbooks during study time:}

In the study the adolescent girl were asked about their parent's reaction if they read books other than textbook during study time. As expected, a large majority of the adolescent girls' parents $\mathrm{N}=78$ reacted negatively and showed irritation but $\mathrm{N}=34$ adolescent girls parents did not show irritation in this case, $\mathrm{N}=4$ sometimes showed irritation, while $\mathrm{N}=3$ adolescent girls mentioned that they do not read other books than text books. The detailed information of the responses is presented in the following table3.3.5 and graphical presentation.

Table 5.3.5 Number and percentage distribution of adolescent girls by their parents irritation if they read books other than text books during study time

\begin{tabular}{|l|l|l|}
\hline Responses & Number & percentage \\
\hline Show irritation & 78 & 65 \\
\hline Do not show irritation & 34 & 28.3 \\
\hline Do not read other than text books & 3 & 2.5 \\
\hline Sometimes show irritation & 4 & 3.3 \\
\hline No response & 1 & .8 \\
\hline Total & $\mathbf{1 2 0}$ & $\mathbf{1 0 0}$ \\
\hline
\end{tabular}

5.4 Family and social Interaction:

5.4.1 Adolescent girls feeling of irritation when their parents do not allow them to watch television: 
Table 5.4.1 Number and percentage distribution of by adolescent girls' feeling of irritation when their parent does not allow them to watch television

\begin{tabular}{|l|l|l|}
\hline Responses & Number & percentage \\
\hline Feel irritated & 60 & 50 \\
\hline Do not feel irritated & 46 & 38.3 \\
\hline Sometimes feel irritated & 10 & 8.3 \\
\hline Not such situation arise & 1 & .8 \\
\hline No response & 2 & 1.7 \\
\hline Do not know & 1 & .8 \\
\hline Total & $\mathbf{1 2 0}$ & $\mathbf{1 0 0}$ \\
\hline
\end{tabular}

In the present study, it was aimed to know adolescent girls 'feeling of irritation when their parents do not allow them to watch television. From the answer to this question, it is observed that $\mathrm{N}=60$ adolescent girls feel irritate $=46$ do not feel irritate, $\mathrm{N}=10$ sometimes feel irritated. The detailed information is given the above table. Finding shows that if adolescent girls are not permitted to watch television, they use to show negative reaction.

5.4.2 Adolescent girls when they go out with family number:

Adolescent girls were also asked questions about their going out with family members. In this connection, they responses given by them indicate that a large number of the adolescent girls $\mathrm{N}=79$ are used to go out with their family members, when some of them $\mathrm{N}=25$ do not go out with their family members. Some of them $\mathrm{N}=11$ sometimes go out with their family members. Details of the results are given in the following table

Table5.4.2 Number and percentage distribution of adolescent girls when they go out with family member

\begin{tabular}{|l|l|l|}
\hline Responses & Number & Percentage \\
\hline Go out with family members & 79 & 65.8 \\
\hline Do not go out with family members & 25 & 21.3 \\
\hline Sometimes go out with family members & 11 & 9.2 \\
\hline Go out without father & 1 & .8 \\
\hline No responses & 4 & 3.3 \\
\hline Total & $\mathbf{1 2 0}$ & $\mathbf{1 0 0}$ \\
\hline
\end{tabular}

Regarding adolescent's girls go out with family members, the findings shows that a large number of adolescent girls are used to go out with their family members and a few of them use to go outside without their family members. This may be clarified in terms of sound and good relationship among the family members in our society.

\subsection{3watchig television of adolescent girls with family members:}

Table 5.4.3 Number and percentage distribution of adolescent girls while watching television together with family members

\begin{tabular}{|l|l|l|}
\hline Responses & Number & Percentage \\
\hline Watch TV with family members & 84 & 70 \\
\hline Do not watch TV with family members & 23 & 19.2 \\
\hline Sometimes watch TV with family members & 10 & 8.3 \\
\hline No responses & 3 & 2.5 \\
\hline Total & $\mathbf{1 2 0}$ & $\mathbf{1 0 0}$ \\
\hline
\end{tabular}

Adolescent girls were asked smellier type of question relating to watching television with their family members. The responses received from them showed in the above table. The table shows that $\mathrm{N}=84$ watch television with family member and $\mathrm{N}=23$ do not watch televising with family members and the detailed information has given in the above table. It is appealing and interesting to say that a large number of adolescents girls use to watch television with family members. This is an indication of a sound and healthy relationship among the family members in our society.

\subsubsection{Gender Discrimination in parents:}

Table 5.4.4 the distribution of gender discrimination in parental behavior

\begin{tabular}{|l|l|l|}
\hline Responses & Number & Percentage \\
\hline Yes & 36 & 30 \\
\hline No & 80 & 66.7 \\
\hline No response & 3 & 2.5 \\
\hline Do not know & 1 & .8 \\
\hline Total & $\mathbf{1 2 0}$ & $\mathbf{1 0 0}$ \\
\hline
\end{tabular}

In this research, it also enquired about family's behavioral pattern and attitude towards adolescent boys and girls. Interestingly enough, the result indicate that a large number of the adolescent girls $\mathrm{N}=80$ confessed that there is no discriminatory behavior and attitudes towards adolescent girls and boys. However, few girls 
confessed that there is discrimination among male and female adolescent their family and parental behavior.

\section{General Discussion}

The chapter is precise of the present investigation, recommendations and suggestion for addressing the relevant issues to parents and adolescent. It appears that most of the adolescent girls opted to the family custom of returning home early in the evening which can be explained in terms of the social security as well as our social and cultural values. Regarding the food habits, the result reveals that a majority of adolescent girl's preferred homemade food and a few of them liked food prepared by their mothers which may be an indicator of deep feelings of love and affectionate relationships between parents and adolescent girls. In connection with talking with friends, most of the adolescent girls did not like to talk with their friends. They felt that telephone should be used for emergency purpose only. In case of long discussion, they can directly visit their friends' residence. It is anticipated that as the participants were from lower middle class group they did not show much interest to telephone talk. One of the interesting and positive findings is that a majority of adolescent girls could offer decision in their family matters, which is an indicator of female empowerment. More than $50 \%$ of adolescent girls were found to feel comfortable at home environment than outside. It is a good sign for both parents and adolescent girls. A majority of the adolescent girls of this study preferred to travel outside with friends. The adolescents of the different social classes are also different because of their upbringing. In this present study the findings reveal that most of the adolescent girls did not show conflicting relation with their parents. The possible reason which can be interpreted in the following ways;

- Changing era may be a powerful influence. Parental disciplinary techniques are more reasonable than they were earlier.

- Influence of mass media and the effect of terrorism have created panic among the parents for which they do not want to have any clashes between them and their daughters.

- Now -a- day's parent`s are more concerned about their adolescent girl`s \& children. As a result parents may think that if clash occur children would go astray. Because they are more emotional, this is the consideration of conflict minimize.

There is a sex difference between boys and girls. Boys are more dominating and their social world is broader than their sisters. They get more input from outside. But our study is on young adolescents girls who are going to X to Xii classes of their areas. They belong to middle class social status where satisfied with what they have and they respect parental value. In this study the participant were from late adolescent group. They have already completed their first journey of adolescence and were exposed to reality facing practical problems in their lives. Therefore, they had some experience and knowledge to cope and adjust with the present competitive society. Moreover, the socio economic factors also could have played a significant role in their life.

\section{Recommendations}

To mitigate and keep away from conflicting relationships, something needs to be done. In this factor, Parent's can let them go on their own but at the same time they should know their ways so that can guide them properly. Perhaps the most sophisticated parents appreciating the need for a delicate balance between freedom and control to achieve balance.

Conflicting relationships can be minimized through positive interaction and communication. It is important aspects of relationships of parents and adolescent promoting.

Mutual understanding enhances any human relationships. Conflicts are stimulated and increased by facial expression, posture, positive silence, tones of voice. As children grow older they are less acceptant of parental restrictions, attitude and more acceptant of rationally motivated restrictions. But when children grow in verbal intelligence, they also were less acceptant of motivate restrictions. It may indicate that either greater maturity brings increased understanding of parents' motivation or greater maturity brings less tolerance for authoritarian retractions or both.

Parents could not give proper time to their childrens as they are quite busy with their social and professional activities. Moreover, when the adolescent seek to gain their identity the development of identity is dependent on how other people react to them especially their parents. Adolescents are naturally at a vulnerable stage with low self-esteem, poor self-image and less satisfied with themselves. So when adolescent try for autonomy and establishment of an identity it is important that they need constructive feedback.

In order to foster healthy and congenial atmosphere in the family parent's adolescent relationships should be smooth, happy and healthy. The following recommendations can be served for this purpose.

* Parents should understand the psychology, requirements, needs, and desires of the adolescents.

* Both parents and adolescents should be free and open to each other

* Adolescents try for autonomy and establishment of an identity

* Effective endeavor and effort should be undertaken for building good moral character. 
* Adolescent girls should understand their parent's views and realize what they want from them

\section{Conclusion}

In addition, there is sometimes a negative impact of media on children from different channel which are not suitable for our culture. Moreover, parents are sometimes too confused to guide and direct their children properly. Considering the above factors, it is suggested that a counseling centre should be established to provide facilities of general counseling for adolescents. This may help them to take decision to solve the problem of adolescent girls adjusting with current challenging and competitive social life. More specifically, the objective s of the centre would be to provide social counseling, educational counseling and counseling for future and career planning. This centre can also help crate congenial atmosphere for relationships, management and other stressful situations. Moreover, seminars, cultural program and trainings can be organized from this centre on the issue.

\section{REFERENCES}

[1] Uma D.Krishnan, M. S. "The Ohio State University”, 2004

[2] Jerelyn, Schultaz, Ph. D. "Disaster Committee", 2003

[3] Lee Mo-Yee, Ph. D. \& Patrick C. McKenry Ph. D.”Adviser Human Ecology” copyright by Uma. D. Krishnan 2004

[4] Arnett, J. J Adolescent and storm stress, reconsidered American Psychologist, 54 317-326 (1999)

[5] BANGLAPEDIA- National Encyclopedia of Bangladesh, Asiatic Society of Bangladesh, Vol:3 CHO-ENT, page 319

[6] Colmen, J.S. The adolescent society, Glencoe Hill, Free press (1991)

[7] Coper, 1998 w.w.w Gogle Search Parent-Adolescent Conflict. htm

[8] Frued, Anna, Adolescence Psychoanalytic Study Child 1998 13, 255-278

[9] Laursen, Coy, \& Collins, Parent Adolescent Conflict, 1998

[10] Mary, J Gander. Harry w. Gardine, Child and Adolescent Development, Little Brown and Company Limited, Canada 1991

[11] Mussen, P.H. Conger, J. J and Kagan, J. J Child Development and Personality ( $3^{\text {rd }}$ ed.) Harper International edition. Harper and Row, New York evanton and London, 1989

[12] Smart, M. S. and Smart R. C Children Development and Relationships, The Macmillan Company, New York: 1989

[13] Youniss \& Smollar 1995 w.w.w. Google Search Parent- Adolescent Conflict. htm Elkind, D Egocentrism in Adolescence, Child Development, 1978 a. 38 1025-35

[14] Erikson, E. H. Identity and Life Cycle:Selected Papers by Erik H. Erikson. 1998 1, 1-165

[15] Jacob, 1974 w.w.w. Google Search Parent-Adolescent Conflict. htm 